\title{
Development of an \\ Extension Advisement Program
}

\author{
Joseph J. Motto \\ University of Michigan, Flint Extension Center
}

IN A RECENT pUblication, Brunner ${ }^{1}$ stated that research in the area of adult education has been too largely neglected by a considerable number of agencies which spend large sums on educational programs. This paucity of research in adult education is true of fundamental research as well as service or programming research which is largely descriptive in character.

As an aspect of programming research, Brunner recommended that any new program of value to adult education be described as it proceeds, as accurately and precisely as possible, and made available to others. The purpose of this report is to describe the University of Michigan resident advisement program at the Flint Extension Center in terms of student needs, and to analyze these needs relative to their implications for extension advisement programs.

\section{The Flint Center Student Population}

In operation for fifteen years, Flint is predominantly a graduate study center. During the 1959-60 academic year, seventy-two per cent of the student enrollment was for graduate credit at the master's, doctor's, or educational specialist levels; ten per cent for undergraduate credit, and eighteen per cent for non-credit and certificate courses. The growth of the Center is indicated by comparing the 385 enrollments for 1944-45 with the total enrollment of 2,498 for the 1959-60 year; an increase of 650 per cent.

Although a variety of courses is offered, the program centers around the education field which accounts for seventy-eight per cent of the total enrollment. Courses in the education field account for fifty per cent of the total yearly course offerings at the Center. Teachers in Flint and environs use the Center for completing the bulk of evening courses leading to a master's degree in education. There is an on-going master's program in engineering which provides for graduate training of the many engineers and technically trained personnel in the area. During the 1959-60 year, 229 students enrolled in engineering classes at the graduate level. With few exceptions, courses are offered only in the late afternoons and evenings to service the fully employed who could not otherwise engage in graduate work. Any of the courses at the Center may be elected by any interested adult without regard to previous educational background, provided that competency prerequisites are met.

In terms of demographic characteristics of the degree student, the population is as follows: mean age, 31.6 years, 79 per cent, married, and aver- 
age number of years since completion of the bachelor's degree, 8.4.

\section{The Advisement Service}

In the past, the administrative supervisor devoted a portion of his time to student advisement, but because of time limitations, procedures were unsystematized and a formal program was not developed. As part of longrange University Extension Service planning, the Center initiated an advisement service in 1958. This was intended to be a pilot program oriented toward analyzing student needs, defining the counselor's role, and integrating the advisement functions with those of administration.

The present advisement service was designed to serve graduate students primarily, but all students requesting services were to be interviewed until the nature of the needs of the Flint student was clarified. As a pilot program, it also made possible obtaining data relevant to the following areas of interest: What needs exist for advisement in a graduate study center whose total yearly population exceeds two thousand? What perceptions of advisement are held by extension students? What student needs, if any, could be met most effectively by a resident advisement program? What range of problems would be presented? What competencies would be required of an adviser who was to service this population?

The answers to these questions were sought to develop a rationale for advisement services in an extension and graduate study center. No attempt was made to define, in advance, the specific qualifications re- quired which would place the Center in its proper perspective in terms of its membership in a total community.

It remains now to examine the response of the student to the advisement service and to derive implications for these data for extension advisement programs in an off-campus setting.

\section{Advisement Service Requests}

The heterogeneity of a university extension center student population results in requests for advisement services which cover a wide range of academic and emotional adjustment problems. The problems presented by advisees fell into ten general categories. The total number of students interviewed over the two year period was 886. The percentage of cases falling into each group is given in the parentheses. For example, of the students seen in advisement over a two year period, thirty-three per cent were educational counseling with admitted graduate students.

1. Admitted graduate degree students requesting assistance in course planning-33\%.

2. Graduate students seeking admission to the university who raise questions about their admissibility $-13 \%$

3. Students who have completed the master's degree, and who desire additional graduate work but are unsure of the area of their interest, or competence, for a postmaster's degree-12\%.

4. Students presenting emotional problems regarding themselves, marital relations, or family adjustment-9\%. 
5. Graduate students who have questions about advanced credit taken at another graduate school, or who plan to take work at another center or institution $-7 \%$.

6. Students presenting problems of emotional adjustment associated directly with performance in an academic program-7\%.

7. Graduate students who have completed the master's program and who seek information about doctoral programs-6\%.

8. Employed adults who have worked for at least five years since college graduation who have specific vocational skill needs relative to their employment yet who have only a secondary interest in a degree program $-4 \%$.

9. Undergraduate students who lack ten hours or less to complete a bachelor's program and who desire to do so through extension $-7 \%$.

10. High school graduates who are drifting in their vocational adjustment, who seek courses providing skills and competencies which will lead to secure and remunerative employment-2\%.

A summary of these requests is presented in Table $I$ in terms of type of service needed:

\section{Table I}

Advisement Service Requests

$\begin{array}{lc}\text { Type } & \text { Per cent } \\ \text { 1. Educational } & 66 \\ \text { 2. Vocational } & 18 \\ \text { 3. Therapeutic } & 9 \\ \text { 4. Personal } & 7\end{array}$

\section{Educational Advisement}

An extension center is committed to assisting its students in identifying opportunities at every level of work offered: credit, non-credit, and service programs. Academic counseling has the purpose of articulating individual student needs with the resources of the center which can meet the needs. Effective advising results in more complete and satisfactory use of extension facilities.

\section{Vocational}

This group contained students at all educational levels. The largest group consisted of those who usually had ten or more hours beyond the master's degree but who were undecided on a vocational goal. A second group consisted of high school graduates in clerical and managerial jobs who wanted to take some college work for vocational skill development. Finally, there were college graduates in professional jobs who sought course work which would prepare them for employment with other companies or agencies or advance them in the same organization. Most of these students had little concept of their interest, ability, and aptitude potentials or the extent to which they were actuating these potentials.

\section{Therapeufic}

These were students who sought professional psychological services for emotional problems which had no direct relationship to academic performance, and whose symptoms influenced their lives in a number of areas of adjustment.

\section{Personal Counseling}

This group consisted of students 
who sought professional psychological services for emotional symptoms which interfered with their academic progress. Included in this group were the underachievers, the compulsive academic perfectionists, and those preoccupied with the specter of failure. In general, these students were functioning well, in no danger of losing personality integrity, and were not experiencing emotional symptoms of disturbance in areas other than the academic program.

\section{Implications For Extension Advisement Programs}

Fully one-third of those requesting services require more than educational counseling. Because of the diversity of counseling problems, the development of an advisement service must make some provision for meeting these needs.

A decision must be made relevant to the counselor's role in relationship to the diversity of counselee needs which will inevitably be encountered. In terms of meeting client needs, the minimum role of the advisement service should be in the nature of a central agency of information regarding community resources to which clients could be referred for appropriate assistance in resolving adjustment problems. In addition to academic counseling, if the service is to provide professional psychological assistance, counselors who have clinical psychological backgrounds as well as experience in academic advisement will be selected.

In outlining qualifications of a counselor at an adult counseling center, Caughlan ${ }^{2}$ suggested the following: Doctorate in Clinical or Counseling Psychology, practicum experience, public school work in the educational field, and experience in a medical setting. A decision will have to be made whether these services will be available to non-students and general community members. This plan also calls for the selection of counselors who, although not possessing the qualifications indicated above, are sensitive to the emotional needs of clients.

The counselor's fund of knowledge must include resources of the community of which the extension center is a part. Any community agency which provides services that fall within the center's goal areas will become, in a sense, an extension of the agency's resources.

"Edmund deS. Brunner, "Adult Education and its Research Needs," Adult Education, Vol. X. Summer 1960, pp. 218-227.

2James C. Caughlan and Daniel W. Fullmer, "Developing a Counseling Center for Adults," Adult Education, Vol. X, Summer 1960, pp. 80-84. 